\title{
Systemic Induction of the Small Antibacterial Compound in the Leaf Exudate During Benzothiadiazole-elicited Systemic Acquired Resistance in Pepper
}

\author{
Boyoung Lee ${ }^{1,2, \dagger}$, Yong-Soon Park ${ }^{2, \dagger}$, Hwe-Su Yi ${ }^{2}$ and Choong-Min Ryu ${ }^{1,2 *}$ \\ ${ }^{\prime}$ Biosystems and Bioengineering Program, University of Science and Technology, Daejeon 305-806, Korea \\ ${ }^{2}$ Molecular Phytobacteriology Laboratory, System and Synthetic Biology Research Center, Korea Research Institute of Bioscience \\ and Biotechnology (KRIBB), Daejeon 305-806, Korea
}

(Received on February 6, 2013; Revised on March 9, 2013; Accepted on March 15, 2013)

\begin{abstract}
Plants protect themselves from diverse potential pathogens by induction of the immune systems such as systemic acquired resistance (SAR). Most bacterial plant pathogens thrive in the intercellular space (apoplast) of plant tissues and cause symptoms. The apoplastic leaf exudate (LE) is believed to contain nutrients to provide food resource for phytopathogenic bacteria to survive and to bring harmful phytocompounds to protect plants against bacterial pathogens. In this study, we employed the pepper-Xanthomonas axonopodis system to assess whether apoplastic fluid from LE in pepper affects the fitness of $X$. axonopodis during the induction of SAR. The LE was extracted from pepper leaves $\mathbf{7}$ days after soil drenchapplication of a chemical trigger, benzothiadiazole (BTH). Elicitation of plant immunity was confirmed by significant up-regulation of four genes, $\mathrm{CaPR1}, \mathrm{CaPR} 4, \mathrm{CaPR}$, and $\mathrm{CaCHI2}$, by BTH treatment. Bacterial fitness was evaluated by measuring growth rate during cultivation with LE from BTH- or water-treated leaves. LE from BTH-treatment significantly inhibited bacterial growth when compared to that from the water-treated control. The antibacterial activity of LE from BTH-treated samples was not affected by heating at $100^{\circ} \mathrm{C}$ for 30 min. Although the antibacterial molecules were not precisely identified, the data suggest that small (less than $5 \mathrm{kDa}$ ), heat-stable compound(s) that are present in BTH-induced LE directly attenuate bacterial growth during the elicitation of plant immunity.
\end{abstract}

Keywords : benzothiadiazole, leaf exudate, pepper, systemic acquired resistance, Xanthomonas axonopodis

Plants protect themselves against virulent and avirulent pathogens and microbes while diverse microbes are exposed in nature (Schneider et al., 1996). The well-characterized and most active plant defense system is the hyper-

\footnotetext{
These authors contributed equally to this work

*Corresponding author.

Phone) +82-42-879-8229, FAX) +82-42-860-4488

E-mail)cmryu@kribb.re.kr
}

sensitive response (HR), which induces rapid programmed cell death at a localized infection site in response to perception of necrotizing non-host pathogens (Mysore and Ryu, 2004). Following HR, systemic acquired resistance (SAR) occurs throughout the whole plant body. In agriculture, SAR has been recognized as a strategy to control plant pathogens because of its evolutionary stability and long-lasting effectiveness against a broad range of pathogens (Deverall, 1995; Hammerschmidt and Kuć, 1995).

A number of chemicals including salicylic acid (SA), methyl jasmonate, $\beta$-aminobutyric acid (BABA), and benzo(1,2,3)-thiadiazole-7-carbothioic acid S-methyl ester (BTH) have been shown to induce SAR in plants (Chen et al., 1993; Davis and Ausubel, 1989; Epple et al., 1997; Vallad and Robert, 2004). Among those, BTH (Friedrich et al., 1996; Lawton et al., 1996) and Probenazole (Yoshioka et al., 2001) are commercial chemical inducers for SAR in plants. The two chemicals have been commercialized under the trade names, such as Actigard ${ }^{\mathrm{TM}}$ and BION for BTH (Kunz et al., 1997) and ORYZEMATE for Probenazole (Meijiseika Co., Tokyo, Japan). Although BTH activates the production of high levels of the defense-related proteins, chitinase, peroxidase, and glucanase, there is a concurrent reduction in the growth of Arabidopsis thaliana (Dietrich et al., 2005). For example, BTH treated wheat plants under field conditions resulted in a reduction of crop yields in the absence of pathogens (Heil et al., 2000), suggesting that a fitness cost to produce defense-related metabolites should be utilized to make a balance between physiological growth and defense machinery (Heil et al., 2000; Heil and Baldwin, 2002).

Upon infection of bacterial and viral pathogens, SAR might be effective to control these pathogens. The mechanism by which BTH treatment reduces bacterial and viral diseases on plants has remained unanswered because antimicrobial activity mediated by BTH has been uncharacterized. Studies with nprl mutant plants, which are unable to accumulate SA, show that BTH functions similarly to $\mathrm{SA}$ in the induction of defense-related gene expression (Friedrich et al., 1996). However, the factors that confer a 
reduction in bacterial population or viral titer in plants during induced resistance are not known. Especially, the significant reduction of the bacterial population cannot be explained by transcriptional expression of defense-related genes.

The objective of this study was to assess the de novo accumulation of antibacterial compound(s) against compatible and incompatible pathovars of Xanthomonas axonopodis from leaf exudate (LE) containing apoplastic fluid (AF) of pepper leaves that had been treated systemically with soil drenching of BTH. The BTH-mediated SAR was validated by up-regulation of defense signaling marker genes such as CaPR1, CaPR4, CaPR9, and CaCHI2. Heat treatment of leaf exudate did not alter its antibacterial activity. Further analysis revealed that the molecular weight of the active ingredient should be less than $5 \mathrm{kDa}$. Although we could not characterize the compound(s), liquid chromatography-mass spectrometry (LC-MS) provided a clear difference at a certain retention time in LE between BTHand water-treated leaves. Our data shows that BTH-treated leaves produce antibacterial metabolites against bacterial pathogens, indicating that certain compound(s) directly respond to bacterial pathogens by inhibition of bacterial growth from LE after occurring SAR.

The seeds of pepper plants (Capsicum annuиm L. cv. Bukwang) were surface sterilized with $6 \%$ sodium hypochlorite, washed four times with sterile distilled water (SDW), and then incubated on MS agar medium (halfstrength) at $25^{\circ} \mathrm{C}$ for 7 days with an $8 \mathrm{~h} \mathrm{light} / 16 \mathrm{~h}$ dark photoperiod until germination. The germinated seeds were transplanted on soilless media (Punong, Co. Ltd., Gyeongju. South Korea) and grown in a growth chamber at $23^{\circ} \mathrm{C}$ with an $8 \mathrm{~h}$ light $/ 16 \mathrm{~h}$ dark photoperiod. The roots of 6-week-old pepper plants were treated with either $10 \mathrm{ml}$ of $0.5 \mathrm{mM}$ benzo-(1,2,3)-thiadiazole-7-carbothioic acid S-methyl ester (benzothiadiazole $=\mathrm{BTH})($ Syngenta, NC, USA) or sterile water. Pepper leaves were collected at 7 days after the BTH or water application.

After BTH treatment for a week, plant leaves were ground in liquid nitrogen, and $200 \mathrm{mg}$ of the powder was used for a single process of RNA isolation. The RNeasy mini kit (QIAGEN) was used to get pure total RNA according to the manufacturer's instruction. The first strand cDNA from the purified total RNA was synthesized by using M-MLV reverse transcriptase (Enzynomics, Daejeon, Korea) at $42^{\circ} \mathrm{C}$ for $1 \mathrm{~h}$. To analyze changes of transcripts, quantitative RT-PCR was conducted using $\mathrm{iQ}^{\mathrm{TM}} \mathrm{CYBR}$ Green Supermix (BIO-RAD, CA, USA) and Chromo 4 (BIO-RAD, CA, USA) with an annealing temperature of $55^{\circ} \mathrm{C}$. The relative transcript abundance was calculated by comparison between the target transcript and the CaACT1 (GenBank accession no. AY572427) transcript. The relative
mRNA expression of $\mathrm{CaPR} 1, \mathrm{CaPR} 4, \mathrm{CaPR} 9$, and $\mathrm{CaCHI} 2$ was examined as reported in previous papers (Park et al., 2001, 2002; Yang et al., 2009). The genes were analyzed using the following primer sets: for CaPR1, 5'-ACTTGC AATTATGATCCACC-3' and 5'-ACTCCAGTTACTGCA

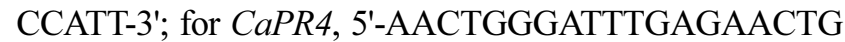
CCAGC-3' and 5'-ATCCAAGGTACATATAGAGCTTCC3'; for CaPR9, 5'-GACTAGTTTCAAGAGCATCA-3' and 5'-AATTGTATAGCCTGTAGCTG-3'; for $\mathrm{CaCHI2,} \mathrm{5'-ATT}$ GGACGATGGAAGCCATCACCAG-3' and 5'-ATATTCC GAATGTCTAAAGTGGTAC-3'; and for CaACT1, 5'-TTG GACTCTGGTGATGGTGTG-3' and 5'-AACATGGTTGA GCCACCACTG-3'.

To collect LE from pepper leaves, the leaves including petioles were cut from the plants, collected, and put in distilled water. After incubation at room temperature for 1 day, the distilled water containing leaf exudate was filter sterilized $(0.22 \mu \mathrm{m}$ pore $)$. The sterilized solution was used for assessment of bacterial growth in LE. The effect of pepper LE on the pathogenicity of a pathogenic bacterium $X$. axonopodis pv. vesicatoria (Xav) and a non-host pathogen X. axonopodis pv. glycinea (Xag) was analyzed. The two pathovars of Xanthomonas were cultivated in LB broth media and washed-out using sterilized distilled water. The bacteria were resolved in the LE solution at a concentration of $200 \mathrm{cfu} / \mathrm{ml}$. After incubation at $30^{\circ} \mathrm{C}$ for 1 day, the solution containing bacteria was spread out on LB agar media and bacterial colonies were counted the next day.

As this was the first trial for identification of inhibitory molecules in pepper LE, we separated exudate into two sizes using membrane filters (Amicon ${ }^{\circledR}$, Millipore, USA) with molecular cut-offs of $10 \mathrm{kDa}$ and $5 \mathrm{kDa}$ and checked their activity to inhibit bacterial growth. The exudate was initially purified with a syringe filter of $0.22 \mu \mathrm{m}$ pore size to remove impurities, and then the purified exudate was separated into two samples using two different sizes of centrifugal filters $(10 \mathrm{kDa}$ and $5 \mathrm{kDa})$. The serial filtering of separated exudate was conducted from $10 \mathrm{kDa}$ to $5 \mathrm{kDa}$ for further analysis. All of the centrifugation steps were performed at 4,000 $\times \mathrm{g}$ (Union 32R, Hanil science medical, Korea) at $4^{\circ} \mathrm{C}$.

In this study, analysis of variance for experimental data sets was performed using JMP software v.5.0 (SAS Institute, Cary, NC, USA). Significant effects of treatment were determined by the magnitude of the $F$ value $(P=0.05)$. When a significant $\mathrm{F}$ test was obtained, separation of means was accomplished by Fisher's protected least significant difference (LSD) at $P=0.05$.

It is known that SAR can be induced by avirulent pathogens (Reglinski et al., 2007) and chemicals (Reignault and Walters, 2007). Specifically, Lawton et al. (1996) demon- 
strated that BTH could induce SAR to virus and bacteria in Arabidopsis. Treatment of tobacco with BTH activates SAR against Tobacco mosaic virus (TMV), Cerospora nicotianae, Pectobacterium carotovorum, Pseudomonas syringae pv. tabaci, and Phytophthora parasitica (Friedrich et al., 1996). Several reports presented that BTH can play a role in inducing strong SAR in response to diverse pathogens in crop plants (Brisset et al., 2000; Görlach et al., 1996; MaxsonStein et al., 2002; Smith-Becker et al., 2003). Recently, it has been reported that BTH applied to pepper plants is likely to enhance plant defenses to even insect pests including whitefly and aphid infestation as well as against microbial pathogens (Lee et al., 2012; Yang et al., 2011).

In our system, the growth parameters of pepper plants treated with $0.5 \mathrm{mM} \mathrm{BTH}$ were similar to water-treated control plants, indicating that $0.5 \mathrm{mM}$ BTH does not have a negative effect on plant fitness in pepper (data now shown). Given that the concentration of BTH used was proper for plants, we tested whether SAR was induced in pepper leaf by soil drench-application of BTH. In general, CaPRI and CaPR9 have been implicated in the SA-dependent signaling pathway, CaPR4 has a role in the jasmonic acid (JA)/ ethylene (ET) pathway, and $\mathrm{CaCHI} 2$ is a marker gene of the ET-related pathway. To confirm SAR induction, transcriptional expression of CaPR1, CaPR4, CaPR9, and $\mathrm{CaCHI} 2$ in pepper seedling leaves was examined by qRTPCR analysis at 7 days after BTH treatment on roots. After normalization of the expression levels of each gene to constitutively expressed CaACT1, the expression of CaPR1, CaPR4, CaPR9, and CaCHI2 was up-regulated by a 4.0-, 12.0-, 22-, and 7.5-fold, respectively, at 7 days after drench-application of $0.5 \mathrm{mM} \mathrm{BTH}$ to roots when compared with water-treated control (Fig. 1). Meanwhile, lower bacterial population in leaves was confirmed in BTH soil-drenched plants (data not shown). The data indicate

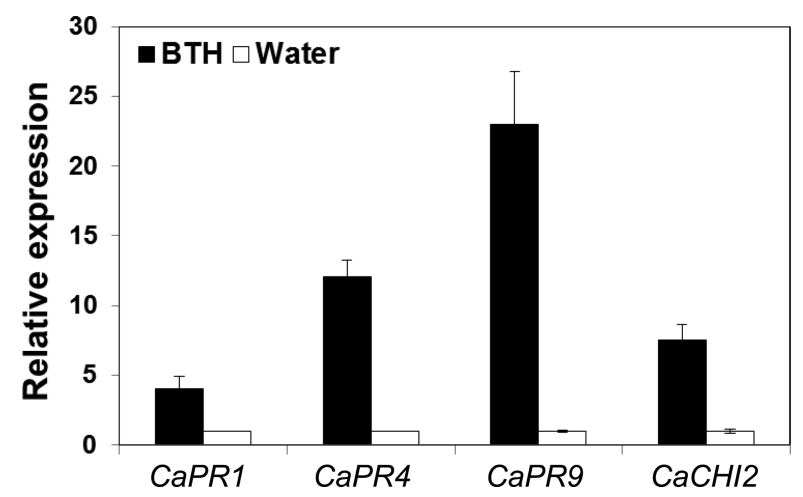

Fig. 1. Confirmation of systemic acquired resistance by BTH in pepper. Expression of defense-related marker genes CaPRl, CaPR4, CaPR9, and CaCHI2 in pepper leaves at 7 days after treatment with BTH on roots (black bars) or water control (white bars) was examined by qRT-PCR. that root-applied BTH can activate induced resistance in leaves, in which the genes involved in SA and JA/ET signaling may be strong candidates for the induction of SAR at the transcriptional level. In contract to our data, the two PRI genes in wheat were not induced by BTH, suggesting that BTH-modulated plant defense may be differentially regulated in monocots as compared to dicots.

Although several pathogenesis-related $(P R)$ genes were induced in pepper leaves after application of BTH on the roots (Fig. 1), additional evidence was necessary for the molecular mechanism of BTH-induced SAR against pathogens. To obtain answers for how SAR-elicited plants are able to actually suppress growth of bacteria, experiments were performed to identify antibacterial substance(s) from systemic tissue during elicitation of SAR by BTH treatment on roots. The trial experiments were conducted to screen appropriate solvents for maximum extraction of leaf exudate (LE) from pepper leaves (data not shown); these experiments showed that water was an effective solvent for leaf exudate within $24 \mathrm{~h}$ at room temperature.

Eventually, the water-based extraction method was selected to extract LE from pepper leaves in sterile plastic boxes at 7 days after root drenching with BTH (Fig. 2A). The same number of two pathogenic bacteria $\left(10^{3} \mathrm{cfu} / \mathrm{ml}\right), \mathrm{Xav}$ (compatible) and Xag (incompatible), was used at $0 \mathrm{~h}$ time point per each treatment. The bacterial number was counted on the LB media by dilution plating method at $24 \mathrm{~h}$ after cultivation in LE. The number of bacteria of Xav and Xag in LE of BTH-treated plants showed an 8.4- and 10.2-fold reduction, respectively, when compared with water-treated plants (Figs. 2B and 2C). The data showed that the level of bacteria population of Xav and Xag was similar to initial number of bacteria but not completely be diminished level, suggesting that unidentified compounds could have a bacteriostatic effect. Next, to evaluate the heat stability of the antibacterial compounds in LE treated with BTH, the collected exudate from water- or BTH-treated plants was boiled at $100^{\circ} \mathrm{C}$ for $30 \mathrm{~min}$. Boiling did not change the antibacterial activity against the two bacterial pathogens. The data showed that a significant reduction of bacterial number was observed in Xav-BTH (16.4-fold) and XagBTH (20.1-fold) (Figs. 2B and 2C).

Although the bacterial growth of Xav and Xag was not affected by heat stress in BTH treated exudate, bacterial fitness of $X a v$ in the boiled water but not Xag was affected (Figs. 2B and 2C). It indicates that any complex forms or long-chain bacterial nutrients (food) can be degraded at high temperature to useful forms for Xav bacterium. Alternatively, antibacterial molecules can be naked to be less active in water-LE to facilitate of Xav rather than Xag. Taken together, any compounds in exudate from BTH treatment can modulate the antibacterial activity to the two 

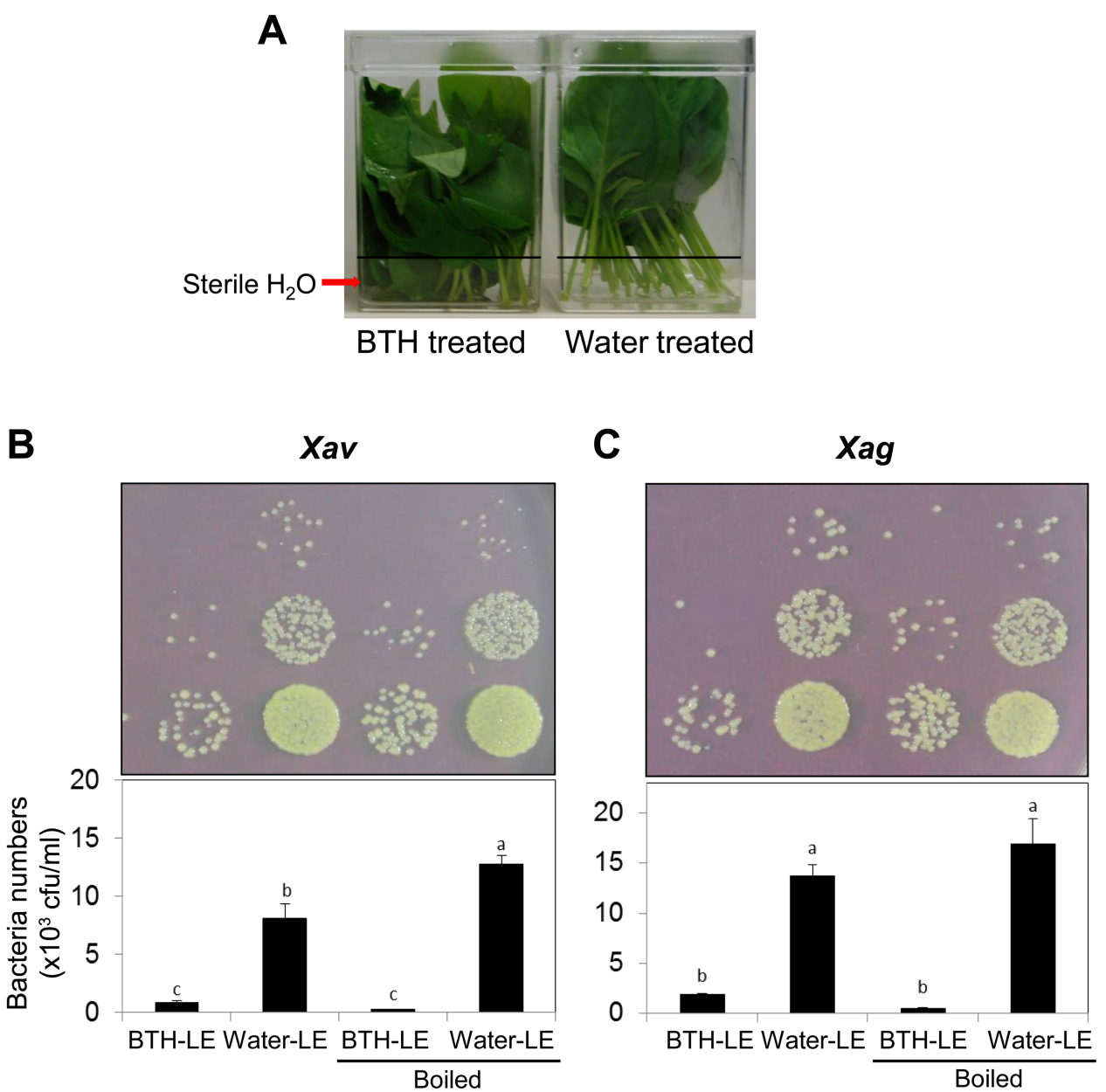

Fig. 2. Leaf exudate (LE) extraction and antibacterial activity assessment. (A) Representative picture of LE extraction method. Antibacterial activity and heat stability of LE on $\operatorname{Xav}(\mathrm{B})$ and $\operatorname{Xag}(\mathrm{C})$. The same number of bacterium $\left(\times 10^{3} \mathrm{cfu} / \mathrm{ml}\right)$ was inoculated for each treatment and colonies of Xav and Xag were then counted 1 day after incubation in exudate. Different letters indicate a significant difference between treatments $(P=0.05)$.

bacterial pathogens, even if exposed to heat stress. In addition, any substances in exudate accumulated by BTH treatment can activate induced resistance to both compatible and incompatible pathogens, suggesting that BTH-treated pepper plants may enhance basal defense to general bacterial pathogens.

To characterize the compounds in LE from water and BTH-treated pepper, the exudates were analyzed by using LC-MS. The data showed that the peaks in chromatograms of BTH-treated pepper plants were different from watertreated pepper plants at approximately 7.36, 21.76, and $29.23 \mathrm{~min}$ retention time (data not shown). Although candidate peaks were identified, the exact name(s) of molecule(s) were not elucidated using our system up to now. Further analyses (i.e., NMR) are remained to characterize the molecular compound(s) that have an antibacterial activity in LE from BTH treated plants.

There are a number of phytoalexins in plants, among which capsidiol is the main bicyclic sesquiterpene in tobacco (Nicotiana tabacum) and pepper (Capsicum annuum) (Maldonado-Bonilla et al., 2008). Also, pepper genes involved in biosynthesis of capsidiol were up-regulated in BTH treated plants when compared with control plants (data now shown). Unexpectedly, no capsidiol was detected in this study. Several possible scenarios were considered to address this aspect. First, the amount of capsidiol is too low to be detected by LC-MS used in this study. Second, the activity of capsidiol could be inhibited by activation of other substances in LE. Alternatively, capsidiol activity may be eliminated under certain conditions of LE used in this study. Finally, the activity of capsidiol in LE may be compromised during modification with post-transcriptional and/or post-translational processing, or in part, concentration of BTH used here could not activate capsidiol.

Although candidate peaks were identified (data not shown), no more information was obtained from previous find- 

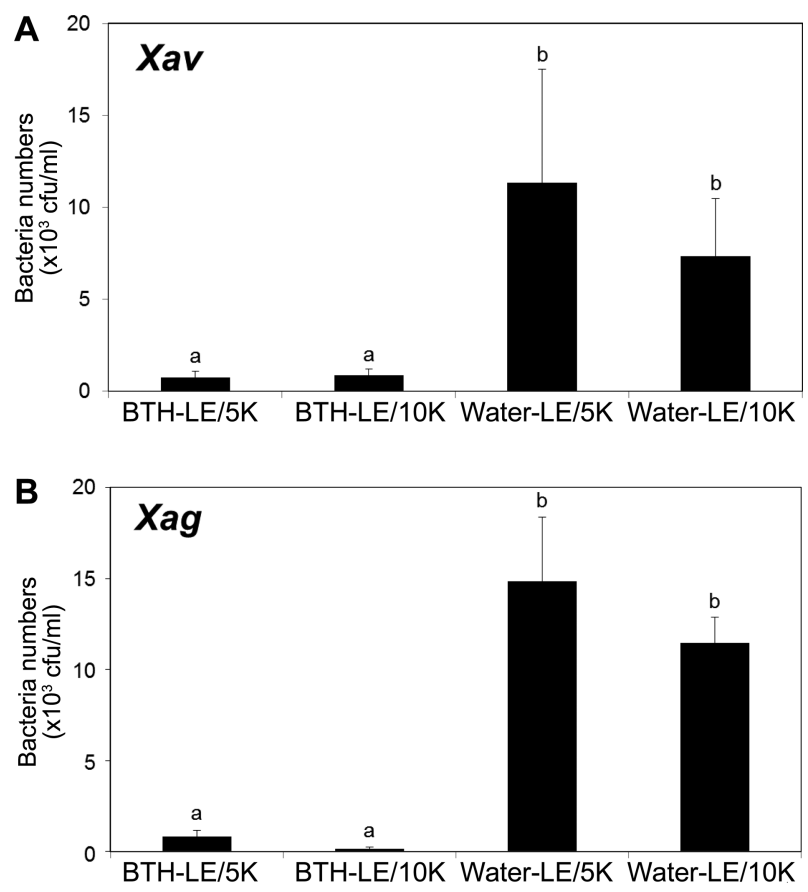

Fig. 3. Size fractionation of antibacterial molecule(s) from leaf exudate (LE). Extracted solution was divided into two samples from $<10 \mathrm{kDa}$ and $<5 \mathrm{kDa}$ using membrane filters. The two fractions were then examined for their antimicrobial activity on $X a v$ (A) and Xag (B). Colonies of Xav and Xag were counted 1 day after incubation in extracted solution. Different letters indicate a significant difference between treatments $(P=0.05)$.

ing. As part of an effort to identify the antibacterial ingredient(s) from BTH treated LE containing AF, the exudate was divided into two samples according to size using membrane filters that have molecular cut-offs at $10 \mathrm{kDa}$ and $5 \mathrm{kDa}$ each. The exudates below $10 \mathrm{kDa}$ and below 5 $\mathrm{kDa}$ were further examined for their inhibition of bacterial growth. After incubation of Xav and Xag in the fractionized exudates for $24 \mathrm{~h}$, the surviving bacteria were counted on agar media. The results showed that fewer bacterial colonies were observed in the BTH treated LE than in the water treated control regardless of the size fractionation and bacterial strains (Figs. 3A and 3B). These results suggest that the size of the inhibitory molecule is small, approximately below $5 \mathrm{kDa}$. Converting the $5 \mathrm{kDa}$ mass into amino acids, which have an average molecular weight of $110 \mathrm{Da}$, the inhibitory molecule is likely to be a peptide consisting of 45 amino acids, with a gene of approximately $135 \mathrm{bp}$ in length. Based on the data, the antibacterial molecules in LE from pepper plants treated with BTH may be small size peptides and may contribute to establishment of initial barriers to attenuate pathogen attacks in local infected tissues as similar to other antimicrobial plant metabolites with low molecular weight (Maldonado-Bonilla et al., 2008). The other possibility is that the levels of carbohyd- rates and/or other nutrients may be changed by BTH treatment and less nutrient levels consequently result in inhibition of bacterial growth as previous research demonstrated that plant nutrients could affect the growth of Pseudomonas syringae (Rico and Preston, 2008).

Our study provides that pepper roots of BTH treatment can enhance SAR in systemic leaves upon inoculation of virulent Xav and avirulent Xag. It is very likely that the broad spectrum effectiveness of SAR by BTH may be caused by de novo production of antibiotic compound(s) in leaf exudate, which are heat-stable and may be smaller than $5 \mathrm{kDa}$. The antibacterial compound(s) may possess the bacteriostatic activity rather than the bactericidal effect.

\section{Acknowledgments}

This research was supported by grants from the Industrial Source Technology Development Program of the Ministry of Knowledge Economy (10035386) of Korea, the NextGeneration BioGreen 21 Program (SSAC grant \#PJ009524), Rural Development Administration, and the KRIBB initiative program, South Korea.

\section{References}

Brisset, M. N., Cesbron, S., Thomson, S. V. and Paulin, J. P. 2000. Acibenzolar-S-methyl induces the accumulation of defenserelated enzymes in apple and protects from fire blight. Eur. J. Plant Pathol. 106:529-536.

Chen, Z., Silva, H. and Klessig, D. F. 1993. Active oxygen species in the induction of plant systemic acquired resistance by salicylic acid. Science 262:1883-1886.

Davis, K. R. and Ausubel, F. M. 1989. Characterization of elicitor-induced defense responses in suspension-cultured cells of Arabidopsis. Mol. Plant-Microbe Interact. 2:363-368.

Deverall, B. J. 1995. Plant protection using natural defence systems of plants. Adv. Plant Pathol. 11:211-228.

Dietrich, R., Ploss, K. and Heil, M. 2005. Growth responses and fitness costs after induction of pathogen resistance depend on environmental conditions. Plant Cell Environ. 28:211-222.

Epple, P., Apel, K. and Bohlmann, H. 1997. Overexpression of an endogenous thionin enhances resistance of Arabidopsis against Fusarium oxysporum. Plant Cell 9:509-520.

Friedrich, L., Lawton, K., Ruess, W., Masner, P., Specker, N., Rella, M. G., Meier, B., Dincher, S., Staub, T., Uknes, S., Métraux, J. P., Kessmann, H. and Ryals, J. 1996. A benzothiadiazole derivative induces systemic acquired resistance in tobacco. Plant J. 10:61-70.

Görlach, J., Volrath, S., Knauf-beiter, G., Henry, G., Beckhove, U., Kogel, K. H., Oosterndorp, M., Staub, T., Ward, E., Kessmann, H. and Ryals, J. 1996. Benzothiadiazole, a novel class of induces of systemic acquired resistance, activates gene expression and disease resistance in wheat. Plant Cell 8:629643. 
Hammerschmidt, R. and Kuć, J. 1995. Induced resistance to disease in plants. Kluwer Academic Publishes, Dordreeht, The Netherlands

Heil, M. and Baldwin, I. T. 2002. Fitness costs of induced resistance: emerging experimental support for a slippery concept. Trends Plant Sci. 7:61-67.

Heil, M., Hilpert, A., Kaiser, W. and Linsenmair, K. E. 2000. Reduced growth and seed set following chemical induction of pathogen defence: Does systemic acquired resistance (SAR) incur allocation costs? J. Ecol. 88:645-654.

Kunz, W., Schurter, R. and Maetzke, T. 1997. The chemistry of benzothiadiazole plant activators. Pes. Sci. 50:275-282.

Lawton, K. A., Friedrich, L., Hunt, M., Weymann, K., Delaney, T., Kessmann, H., Staub, T. and Ryals, J. 1996. Benzothiadiazole induces disease resistance in Arabidopsis by activation of the systemic acquired resistance signal transduction pathway. Plant J. 10:71-82.

Lee, B., Lee, S. and Ryu, C.-M. 2012. Foliar aphid feeding recruits rhizosphere bacteria and primes plant immunity against pathgenic and non-pathogenic bacteria in pepper. Ann. Bot. 110:281-290.

Maldonado-Bonilla, L. D., Betancourt-Jimeinez, M. and LozoyaGloria, E. 2008. Local and systemic gene expression of sesquiterpene phytoalexin biosynthetic enzymes in plant leaves. Eur. J. Plant Pathol. 121:439-449.

Maxson-Stein, K., He, S.-Y., Hammerschmidt, R. and Jones, A. L. 2002. Effect of treating apple trees with acibenzolar-S-methyl on fire blight and expression of pathogenesis-related protein genes. Plant Dis. 86:785-790.

Mysore, K. S. and Ryu, C.-M. 2004. Nonhost resistance: how much do we know? Trends Plant Sci. 9:97-104.

Park, C. J., Shin, R., Park, J. M., Lee, G. J., Yoo, T. H. and Paek, K. H. 2001. A hot pepper cDNA encoding a pathogenesisrelated protein 4 is induced during the resistance response to tobacco mosaic virus. Mol. Cells 11:122-127.

Park, C. J., Shin, R., Park, J. M., Lee, G. J., You, J. S. and Paek, K. H. 2002. Induction of pepper cDNA encoding a lipid transfer protein during the resistance response to tobacco mosaic virus. Plant Mol. Biol. 48:243-254.

Reglinski, T., Dann, E. and Deverall, B. 2007. Intergration of induced resistance in crop production. In Induced resustance for plant defence, A sustainable approach to crop protection. Blackwell publishing, Oxford, UK, pp 201-228.

Reignault, P. and Walters, D. 2007. Tropical application of inducers for disease control. In Induced resustance for plant defence, A sustainable approach to crop protection. Blackwell publishing, Oxford, UK, pp 179-200.

Rico, A. and Prestion, G. M. 2008. Pseudomonas syringae pv. tomato DC3000 uses constitutive and apoplast-induced nutrient assimilation pathways to catabolize nutrients that are abundant in the tomato apoplst. Mol. Plant-Mictobe Interact. 21:269-282.

Schneider, M., Schweizer, P., Meuwly, P. and Metraux, J. 1996. Systemic acquired resistance in plants. Int. Rev. Cyt. 168:303340.

Smith-Becker, J., Keen, N. T. and Becker, J. O. 2003. Acibenzolar-S-methyl induces resistanct to Colletotrichum lagenarium and cucumber mosaic virus in cantaloupe. Crop Prot. 22:769-774.

Vallad, G. E. G. and Robert, M. 2004. Systemic acquired resistance and induced systemic resistance in conventional agriculture. Crop Sci. 44:1920.

Yang, J. W., Yu, S. H. and Ryu, C.-M. 2009. Priming of defenserelated genes confers root-colonizing Bacilli-elicited induced systemic resistance in pepper. Plant Pathol. J. 25:389-399.

Yang, J. W., Yi, H.-S., Kim, H., Lee, B., Lee, S., Ghim, S.-Y. and Ryu, C.-M. 2011. Whitefly infestation of pepper plants elicits defense responses against bacterial pathogens in leaves and roots and changes the below-ground miroflora. J. Ecol. 99:4656.

Yoshioka, K., Nakashita, H., Klessig, D. F. and Yamaguchi, I. 2001. Probenazole induces systemic acquired resistance in Arabidopsis with a novel type of action. Plant J. 25:149-157. 